Document downloaded from:

http://hdl.handle.net/10251/100332

This paper must be cited as:

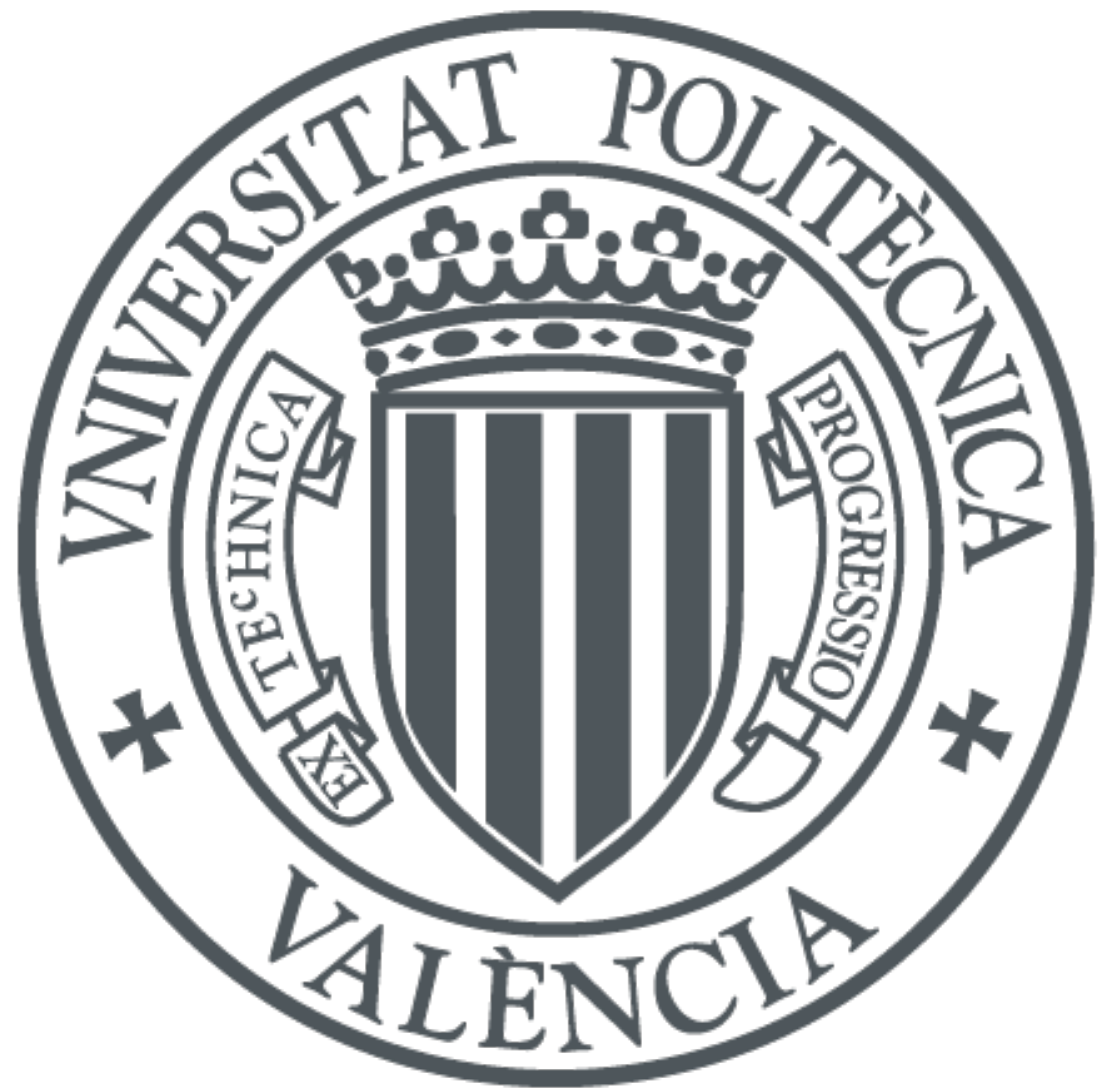

The final publication is available at

http://doi.org/10.1111/sjop.12136

Copyright Blackwell Publishing

Additional Information

This is the pre-peer reviewed version of the following article: Moret-Tatay, Carmen, MorenoCid, Amparo, Iracema de Lima Argimon, Irani , Quarty Irigaray, Tatiana, Szczerbinski, Marcin , Murphy, Mike, Vázquez-Martínez, Andrea, Vázquez-Molina, Joan , Saiz Mauleón, María Begoña, Navarro Pardo, Esperanza, Fernández de Córdoba, Pedro. (2014). The effects of age and emotional valence on recognition memory: An ex-Gaussian components analysis.Scandinavian Journal of Psychology, 55, 5, 420-426. DOI: 10.1111/sjop.12136, which has been published in final form at http://doi.org/10.1111/sjop.12136. This article may 


\title{
The effects of age and emotional valence on recognition memory: An ex-Gaussian components analysis
}

\author{
CARMEN MORET-TATAY, ${ }^{1}$ AMPARO MORENO-CID, ${ }^{2}$ IRANI IRACEMA DE LIMA ARGIMON,${ }^{3}$ TATIANA QUARTI \\ IRIGARAY, ${ }^{3}$ MARCIN SZCZERBINSKI, ${ }^{4}$ MIKE MURPHY, ${ }^{4}$ ANDREA VÁZQUEZ-MARTINEZ, ${ }^{2}$ JOAN VAZQUEZ-MOLINA, ${ }^{5}$ \\ BEGOÑA SÁIZ-MAULEÓN, ${ }^{5}$ ESPERANZA NAVARRO-PARDO ${ }^{2}$ and PEDRO FERNÁNDEZ DE CÓRDOBA CASTELLÁ ${ }^{5}$ \\ ${ }^{1}$ Universidad Católica de Valencia “San Vicente Mártir”, Spain \\ ${ }^{2}$ Universitat de Valencia, Spain \\ ${ }^{3}$ Pontificia Universidade Católica do Rio Grande do Sul, Brazil \\ ${ }^{4}$ University College Cork, Ireland \\ ${ }^{5}$ Universitat Politécnica de Valencia, Spain
}

Moret-Tatay, C., Moreno-Cid, A., Argimon, I. I. L., Quarti Irigaray, T., Szczerbinski, M., Murphy, M., Vázquez-Martínez, A., Vázquez-Molina, J., SaízMauleón, B., Navarro-Pardo, E. \& Fernández de Córdoba Castellá, P. (2014). The effects of age and emotional valence on recognition memory: An exGaussian components analysis. Scandinavian Journal of Psychology.

The aim of this work was to study the effects of valence and age on visual image recognition memory. The International Affective Picture System (IAPS) battery was used, and response time data were analyzed using analysis of variance, as well as an ex-Gaussian fit method. Older participants were slower and more variable in their reaction times. Response times were longer for negative valence pictures, however this was statistically significant only for young participants. This suggests that negative emotional valence has a strong effect on recognition memory in young but not in old participants. The $\mathrm{s}$ parameter, often related to attention in the literature, was smaller for young than old participants in an ex-Gaussian fit. Differences on the $\mathrm{S}$ parameter might suggest poorer attentional performance in old participants.

Key words: Ex-Gaussian components, age, emotional valence, recognition.

Moret-Tatay, C., Facultad de Psicología, Magisterio y Ciencias de la Educación, Universidad Católica de Valencia 'San Vicente Mártir', Sede de San Juan Bautista, Avenida Guillem de Castro 175, 46008, Valencia, Spain. E-mail: carmenmoret@gmail.com

\section{INTRODUCTION}

Humans regularly face emotionally charged stimuli. Thus, not surprisingly, the study of the impact of valence on memory has attracted the interest of cognitive psychology in the last decades. A useful tool regarding the nature of the stimuli is the International Affective Picture System, developed by Peter J. Lang at Florida University (1999). The success of this battery is determined by its high reliability in terms of emotional valence (the pleasantness of the stimulus), arousal (the intensity of emotion provoked by the stimulus), and dominance (the degree of control exerted by the stimulus). Most of the research that has employed the IAPS battery has analyzed response times (RTs) and percentage of errors or correct responses as the dependent

variable (Borg, Leroy, Favre, Laurent \& Thomas-Antérion, 2011; Charles, Mather \& Carstensen, 2003; Gordillo Leon, Arana, Mestas et al., 2010).

RT usually shows a high sensitivity to cognitive processes, but its distribution is often positively skewed, which is problematic for some methods of statistical analysis. However, skewed RTs can be described adequately by use of an ex-Gaussian distribution. The advantage of this analysis lies in the fact that its three parameters may map onto different cognitive processes, although the functional interpretation of those parameters is still debated in the literature (Matzke \& Wagenmakers, 2009). The parameter that arguably attracts the greatest research interest is S. It has been described as a perceptual aspect of a RT (Hohle, 1965), a decision component (Luce, 1986) and more recently, an attentional component or a defective effort control mechanism (Leth-Steensen, King Elbaz \& Douglas, 2000).

Mathematically, the ex-Gaussian probability density function is the result of a combination of two random variables, a Gaussian distribution (described by its I and $\mathbf{r}$ parameters), and an exponential distribution (described by its $s$ parameter). Thereby, an ex-Gaussian distribution is perfectly defined with three parameters: the first two ( $\mathbf{I}$ and $\mathbf{r}$ ), are the mean and standard deviation of the Gaussian component, while the third parameter (s) is the rate parameter of the exponential component. When analyzing the results from an ex-Gaussian fit, one must be careful because the parameters that describe the mean distribution are $\mathbf{I}+\mathrm{s}$. Ratcliff and Murdock (1976) and Luce (1986) showed that the ex-Gaussian function provides a good fit to several empirical reaction times distributions and it continues to be used as a tool for the analysis of RT data (Epstein, Langberg, Rosen et al., 2011; Navarro-Pardo, Navarro-Prados, Gamermann \& MoretTatay, 2013). While many researchers have related ex-Gaussian components to underlying cognitive processes, the literature is limited in terms of how the processing of emotional valence of stimuli may affect the three parameters of the ex-Gaussian distribution.

Several studies employing traditional methods (Buchanan \& Adolphs, 2002; Reisberg \& Heuer, 2004) have shown evidence that emotional content of visual stimuli has an impact on recognition. Rozin and Royzman (2001) stated that given positive and negative stimuli of equal objective magnitude, negative emotion is more potent. This idea is supported by Wright, Busnello, 
Buratto and Stein (2012), who found more accurate responses with negative valence when studying a memory conformity effect. However, this emotional modulation of memory processes may be age-dependent. Charles et al. (2003) carried out two experiments where the valence of stimuli was manipulated. They found age-related reduction in memory for negative images. The reduction affected both kinds of stimuli, but it was more prominent for the negative ones. Moreover, attempts have been made to examine interactions between cognitive processes such as attention and emotion through the presentation of visual material. Some researchers concluded that such interactions could activate visual processing (Keil, Bradley, Hauk, Rockstroh, Elbert \& Lang, 2005; Schupp, Stockburger, Codispoti, Junghofer, Weike \& Hamm, 2007).

In the current study, we employ an alternative methodology to estimate the role of valence in terms of ex-Gaussian components and aging. To this end, a picture recognition task was conducted. Young and old participants were first exposed to different IAPS images (hereafter called target images) selected for their valence, and after a distracting interval, they were requested to differentiate the target images from other images (hereafter called distracting images). The aim of the study is to examine the impact of two factors: emotional valence of stimuli, and participants' age, on recognition memory. The data are analyzed using an exGaussian components method, since it allows for appropriate modeling of skewed data, as well as modeling of distinct cognitive processes affecting RT performance.

\section{METHOD}

\section{Participants}

A sample of 40 young university students volunteered to take part in experiment 1 (32 women and 8 men with mean age of 22.23 years and $\mathrm{SD}=2.12)$.

In experiment 2, a sample of 40 senior university students from a program for aged students, volunteered to take part (29 women and 11 men, mean age of 67.29 years and $S D=6.19$ ).

Six participants in experiment 2 were replaced due to an error rate of higher than $40 \%$. All participants had normal or corrected to normal vision, were native Spanish speakers and did not report cognitive impairment or neurological disorders. The sample selected for both groups has a female majority, but there is no reason to believe that processes addressed in this research might be gender dependent.

\section{Materials}

The stimuli used were a selection of photographs from the International Affective Picture System (IAPS, CSEA-NIMH, 1999; Lang, Bradley \& Cuthbert, 1999) in the Spanish adaptation of Moltó, Montañes, Poy et al. (1999). We selected a total of 120 photographs divided into three sets of 40 photographs based on their scores on valence (positive, negative or neutral). For the purpose of the recognition task, from the 120 images selected, 60 were selected as the target images and 60 as distracting ones. In each set, 20 were neutral images, 20 images were negative and 20 were positive images (see Table 1 ).

\section{Procedure}

Participants were tested in a quiet room, in groups of three or four people. The presentation of stimuli and recording of response times were
Table 1. Mean valence and arousal values for the selected images in the different sets from the Spanish adaptation of Molto et al. (1999)

\begin{tabular}{llrrc}
\hline & & \multicolumn{1}{c}{ Neutral } & \multicolumn{1}{c}{ Negative } & Positive \\
\hline Target & Valence & $5(0.45)$ & $2.82(0.75)$ & $7.2(0.6)$ \\
& Arousal & $5(0.46)$ & $6.1(0.77)$ & $4.8(1.2)$ \\
Distracting & Valence & $5.05(0.58)$ & $2.82(0.65)$ & $7.2(0.5)$ \\
& Arousal & $4(0.82)$ & $5.9(0.91)$ & $5.1(1.3)$ \\
Total & Valence & $5.03(0.51)$ & $2.82(0.69)$ & $7.2(0.54)$ \\
& Arousal & $4(0.66)$ & $6(0.84)$ & $5(1.2)$ \\
& & & & \\
\hline
\end{tabular}

Note: Standard deviation in parenthesis.

controlled by a Windows operating system through DMDX software (Forster \& Forster, 2003). The experiment consisted of two phases. In the first phase, the 60 target stimuli were presented randomly (20 stimuli for each of the three valence categories) with short exposures of $2 \mathrm{sec}-$ onds each. In the second phase (15 minutes after the participants were distracted by performing visual search tasks), the 60 target stimuli plus the 60 distracting stimuli were randomly presented to the participants. Each image was presented until the participant gave a response or $2000 \mathrm{~ms}$ passed. The participants were instructed to press a button (labelled "Yes") to indicate whether the stimulus was a target stimulus, and press another button (labelled "No") if the stimulus was a distracting stimulus (did not appear in the first phase).

The participants were also instructed to respond as quickly as possible while maintaining a reasonable level of accuracy. The session lasted approximately 40 minutes.

\section{Design and data analysis}

Two different analyses were carried out. A classical analysis of variance (ANOVA) explored the impact of stimulus identity (target or distractor), emotional valence (neutral, positive and negative) and participants' age on response latency. The same procedure was employed for error rates. This was followed by the fitting of RT data to an ex-Gaussian distribution function. For the latter analysis, data sets were distributed in intervals in order to create a histogram. Differences between parameters from the ex-Gaussian fit were analyzed regarding their uncertainties (errors) as confidence interval lengths for each parameter.

\section{RESULTS}

The statistical analysis was performed using SPSS statistical software version 20 (IBM, Armonk, NY). Table 2 presents the reaction times average (ms), error rates and standard deviations for each group of images.

The ANOVAs were performed after reaction times below $250 \mathrm{~ms}$ and above $1800 \mathrm{~ms}$ were excluded. The $1800 \mathrm{~ms}$ cut-off point was adopted for consistency with earlier studies in the field (Moret-Tatay \& Perea, 2011; Navarro-Pardo et al., 2013). This excluded data constituted $3.3 \%$ and $5.6 \%$ of responses for young and old participants, respectively. The ex-Gaussian distribution characterization used all data. Reaction times corresponding to incorrect responses were excluded from all analyses.

The classical analysis of variance (ANOVA) was performed using a 29293 mixed design, with a between-subject factor of Age (young vs old) and within-subject factors of stimulus Identity (target vs distractor) and Valence (neutral positive and negative).

The ANOVA carried out on RT data showed a main effect of Age: $F(1,78)=6.690$, MSE $=112284.91, g^{2}=0.08, p<0.05$, Identity: $F(1,78)=128.311, \mathrm{MSE}=8106.68, \mathrm{~g}^{2}=0.62$, 
Table 2. Response time averages (ms), error rates for each experimental condition

\begin{tabular}{|c|c|c|c|c|c|}
\hline \multirow[b]{2}{*}{ Group } & \multirow[b]{2}{*}{ Stimulus identity } & & \multicolumn{3}{|c|}{ Stimulus valence } \\
\hline & & & Neutral & Negative & Positive \\
\hline \multirow[t]{6}{*}{ Young } & Target & M & 808.08 & 834.71 & 806.62 \\
\hline & & SD & 78.65 & 82.53 & 69.11 \\
\hline & & Errors & $16 \%$ & $17 \%$ & $19 \%$ \\
\hline & Distracting & M & 854.01 & 917.25 & 899.58 \\
\hline & & SD & 98.62 & 111.95 & 100.23 \\
\hline & & Errors & $3 \%$ & $5 \%$ & $4 \%$ \\
\hline \multirow[t]{6}{*}{ Old } & Target & M & 871.57 & 890.49 & 866.82 \\
\hline & & SD & 197.72 & 207.29 & 178.10 \\
\hline & & Errors & $16 \%$ & $19 \%$ & $20 \%$ \\
\hline & Distracting & M & 968.49 & 1004.46 & 993.12 \\
\hline & & SD & 186.45 & 184.84 & 179.81 \\
\hline & & Errors & $11 \%$ & $14 \%$ & $17 \%$ \\
\hline
\end{tabular}

$p<0.001$, and Valence: $F(2,77)=15.460$, MSE $=3623.77$, $g^{2}=0.17, p<0.001$. Old participants were slower than the young ones ( $\mathrm{M}=932$ and $853 \mathrm{~ms}$, respectively), target (previously presented) stimuli were responded to faster than the distractors ( $\mathrm{M}=846$ and $939 \mathrm{~ms}$, respectively). Bonferroni pairwise comparisons indicated that the negative images ( $\mathrm{M}=912 \mathrm{~ms}$ ) were responded to significantly more slowly ( $p<0.01)$ than the positive ones $(\mathrm{M}=892 \mathrm{~ms})$ and the neutral ones $(\mathrm{M}=876 \mathrm{~ms})$, while the difference between the latter two was approaching significance ( $p=0.053$ ). These main effects were qualified by the interactions between stimulus Identity and Age: $F(1,78)=5.511, p=0.021, g^{2}=0.07$, as well as Identity and Valence: $F(2,77)=5.339, p=0.007, \mathrm{~g}^{2}=0.07$.

The ANOVA carried out on accuracy showed a main effect of Age: $F(1,78)=7.49$, MSE $=2613.33, g^{2}=0.08, p<0.05$, and Identity: $F(1,78)=18.19$, MSE $=6348.01, \mathrm{~g}^{2}=0.18, p<0.001$, however, Valence did not reach the significance level $(F<1)$.

In order to explore those interactions, 293 Identity 9 Valence ANOVAs were carried out, separately for young and old participants.

\section{Young}

The ANOVA on RT data of young participants revealed main effects of Identity: $F(1,39)=39.205 ; \mathrm{MSE}=8336.86 ; \mathrm{g}^{2}=0.50$; $p<0.001$, as well as Valence: $F(2,78)=25.687$; MSE $=$ 1586.29; $g^{2}=0.40 ; p<0.001$. Target stimuli were processed faster $(\mathrm{M}=816 \mathrm{~ms})$ than distractors $(\mathrm{M}=890 \mathrm{~ms})$, and Bonferroni pairwise comparisons indicated that negative stimuli ( $\mathrm{M}=876 \mathrm{~ms}$ ) were processed more slowly than positive ones ( $\mathrm{M}=853 \mathrm{~ms}$ ), which in turn were processed more slowly than neutral ones $(\mathrm{M}=831 \mathrm{~ms}$ ) (all $p s<0.01)$. The interaction between Valence and Identity was significant: $F(2,78)=8.588$, MSE $=1528.50 ; g^{2}=0.18 ; p<0.001$. Bonferroni pairwise comparisons indicated that, for the target stimuli, negative ones ( $\mathrm{M}=835 \mathrm{~ms}$ ) were processed more slowly $(p<0.05)$ than both positive $(\mathrm{M}=808 \mathrm{~ms})$ and neutral ones $(\mathrm{M}=807 \mathrm{~ms})$, with no significant difference ( $p>0.50$ ) between the latter two categories. For the distractor stimuli, negative ones $(\mathrm{M}=917 \mathrm{~ms})$ were also processed more slowly $(p<0.01)$ than neutral ones ( $p=0.854 \mathrm{~ms}$ ), but not significantly more slowly ( $p>0.10$ ) than positive ones $(\mathrm{M}=900 \mathrm{~ms})$. Error differences did not reach statistical significance for valence $(F<1)$ but it did for distracting and target conditions: $F(1,39)=60.79$, MSE $=11.21$,

$g^{2}=0.60 ; p<0.001$.

\section{Old}

The ANOVA on the latencies of old participants also revealed significance for the main factor of Identity: $F(1,39)=96.236$; MSE $=7876.49 ; g^{2}=0.71 ; p<0.001$, but it fell just short of significance for the main factor of emotional Valence: $F(2,78)=2.95 ;$ MSE $=5905.85 ; g^{2}=0.07 ; p=0.058$. The interaction between Identity and Valence was not significant, either: $F(2,78)=1.103$, MSE $=4074.59, g^{2}=0.03$. Thus, the target stimuli were processed faster than the distractors $(\mathrm{M}=876$ vs. $989 \mathrm{~ms}$, respectively), but there was no significant differences between the processing of negative ( $\mathrm{M}=947 \mathrm{~ms}$ ), positive ( $\mathrm{M}=930 \mathrm{~ms}$ ) and neutral $(\mathrm{M}=920 \mathrm{~ms})$ stimuli - albeit the direction of those differences was the same as in the young group. Thus, the impact of valence on RT appears to be much more prominent in the young group. Error differences did not reach statistical significance for distracting and target conditions $(F<1)$ but it did for valence: $F(2,78)=5.41$;

MSE $=428.22 ; g^{2}=0.12 ; p<0.05$. Bonferroni pairwise comparisons indicated that positive stimuli $(M=81.31)$ were processed more accurately than neutral ones $(M=85.93)$, ps $<0.05$.

Table 3. I, r, s parameters with their uncertainty (standard error), dfs (degrees of freedom) and the ratio between v2/df for each condition

\begin{tabular}{|c|c|c|c|c|c|c|c|}
\hline Group & Stimulus identity & Stimulus valence & $\mathbf{I}$ & $r$ & $\mathrm{~S}$ & df & $\mathrm{v} 2 / \mathrm{df}$ \\
\hline \multirow[t]{6}{*}{ Young } & \multirow[t]{3}{*}{ Target } & Neutral & 620.06 T 6.47 & $52.61 \mathrm{~T} 4.97$ & 181.50 T 10.08 & 22 & 1.01 \\
\hline & & Negative & 640.33 T 6.50 & 60.91 T 5.41 & 185.55 T 10.14 & 25 & 0.84 \\
\hline & & Positive & 639.14 T 6.22 & $64.01 \mathrm{~T} 4.45$ & 159.96 T 8.39 & 28 & 0.73 \\
\hline & \multirow[t]{3}{*}{ Distractor } & Neutral & 656.34 T 8.67 & 74.71 T 6.59 & 186.11 T 11.84 & 27 & 1.26 \\
\hline & & Negative & $710.03 \mathrm{~T} 11.02$ & 95.15 T 10.01 & 197.07 T 15.03 & 27 & 1.34 \\
\hline & & Positive & 681.10 T 8.04 & 81.91 T 6.04 & 215.66 T 11.22 & 30 & 0.89 \\
\hline \multirow[t]{6}{*}{ Old } & \multirow[t]{3}{*}{ Target } & Neutral & 597.68 T 7.20 & 58.54 T 6.72 & 257.81 T 13.29 & 34 & 0.87 \\
\hline & & Negative & 611.46 T 9.43 & 57.43 T 8.24 & 248.48 T 18.26 & 32 & 1.45 \\
\hline & & Positive & 604.42 T 9.32 & 61.42 T 8.45 & 235.51 T 16.55 & 32 & 1.37 \\
\hline & \multirow[t]{3}{*}{ Distractor } & Neutral & 660.12 T 10.26 & 97.11 T 8.83 & 307.96 T 16.62 & 37 & 0.85 \\
\hline & & Negative & 704.45 T 11.55 & 91.72 T 9.39 & 308.46 T 18.25 & 37 & 1.06 \\
\hline & & Positive & 680.65 T 12.73 & 104.6 T 10.01 & 315.33 T 19.1 & 36 & 1.01 \\
\hline
\end{tabular}


Finally, we proceeded to characterize the reaction times by an ex-Gaussian fit. One should keep in mind that $\mathbf{I}$ and $\boldsymbol{r}$ are not the average and standard deviation of the ex-Gaussian distribution, which should be calculated via the three parameters that describe the distribution: the mean is in fact $\bar{M}=\mathbf{I}+$ S.

Fitting the distribution means finding the optimal values for the parameters I, S and $\mathbf{r}$ that best describe the experimental data. For this purpose, we used the fitting function of the opensource software Gnuplot. With this software, the fit of any mathematical function to any data set can be obtained straightforwardly by a single function, but given the amount of data in the present work, the need to prepare the data (distribute it in intervals) and
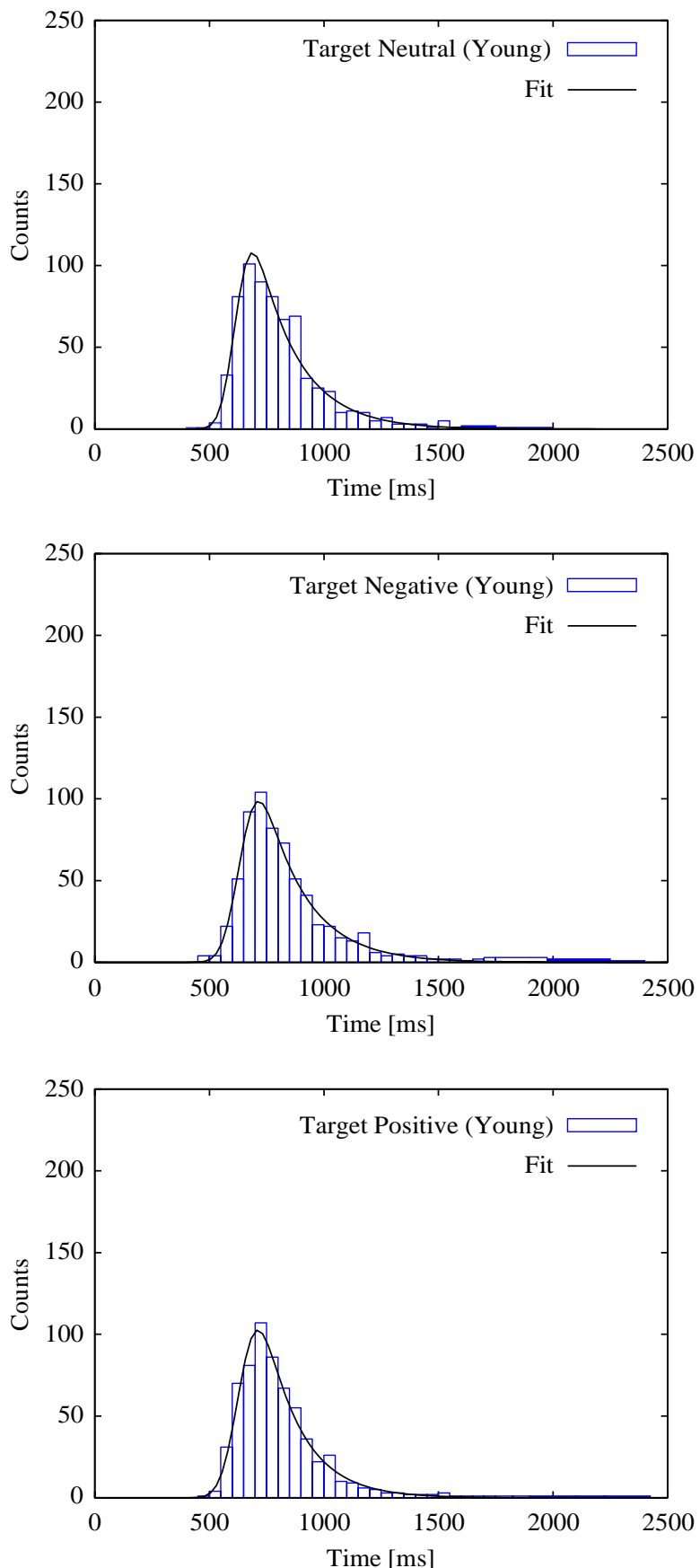

the fact that many different datasets had to be fitted, a python script was programmed. This script automatically reads a set of data (reaction times), groups this data in intervals, creating a histogram and interacts with the Gnuplot software in order to fit an ex-Gaussian function to the data points. Distribution fits and graphics were both executed by the command-line program GNU plot 4.2 (via Navarro-Pardo et al., 2013). The Gnuplot software employs the Levenberg-Marquardt algorithm, also known as dumped least-square method (Marquardt, 1963). The algorithm finds the optimal parameters that minimize the square of the difference between a given data set $\left(x_{i}, y_{i}\right)$ and a target function $f\left(x_{i}\right)$.
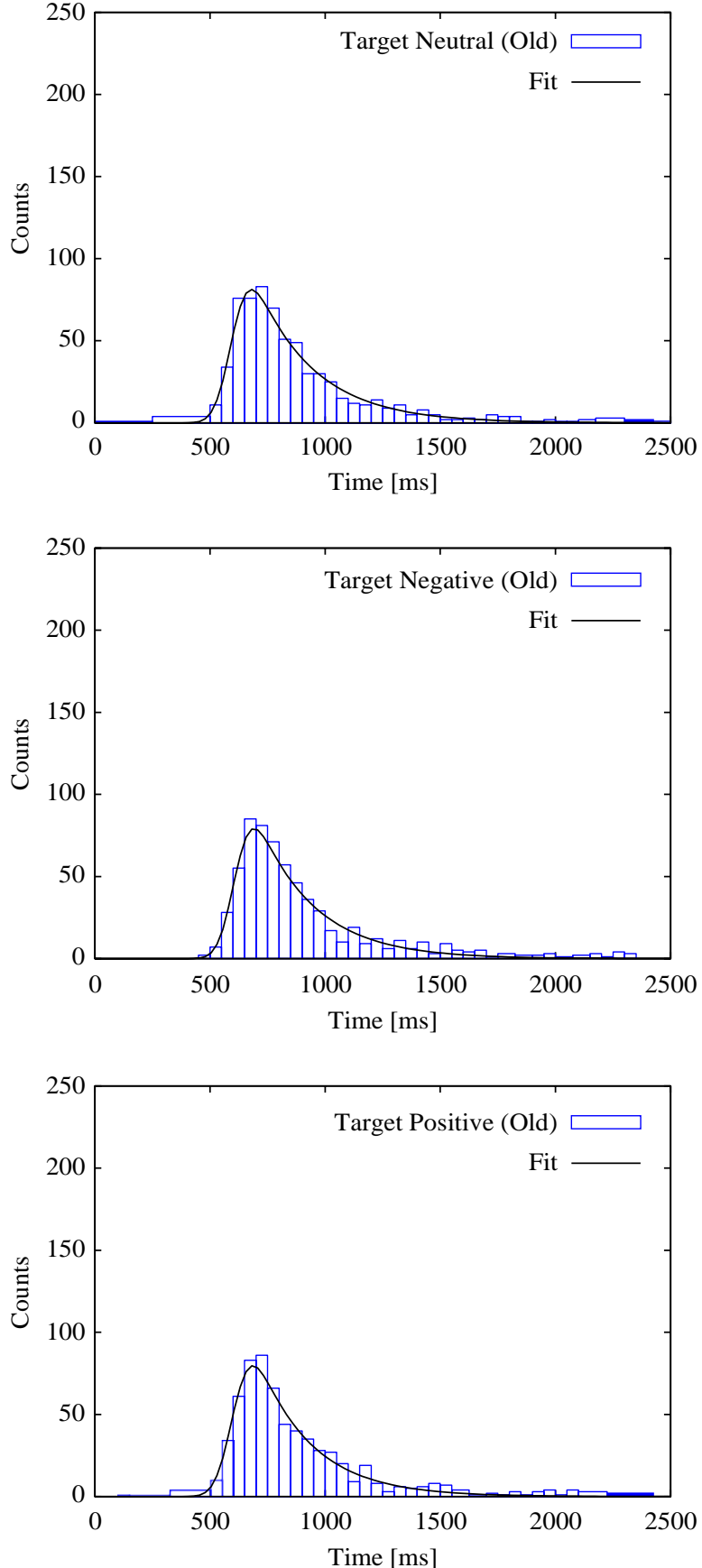

Fig. 1. Reaction times for each target condition, together with the ex-Gaussian fit. Left side: Young participants. Right side: Old participants. Top: neutral condition. Middle: negative condition. Bottom: positive condition. 
The algorithm is an iterative procedure that readjusts the set

of parameters in each iteration. First of all, a goodness of fit

function has to be defined in order to reflect the quality of the fit. The goodness of fit can be evaluated through the residual variance (the most widely used method in behavioral sciences, $\mathrm{V}^{2} /$ degrees of freedom). Smaller values are preferable as they reflect a better fit. Table 3 shows the different parameters obtained by the fitting procedure and Figs. 1 and 2 show the graphical representation of the histograms, together with fit, for each condition.

The uncertainties (errors) presented in Table 3, allow us to compare the parameters for the different conditions, regarding
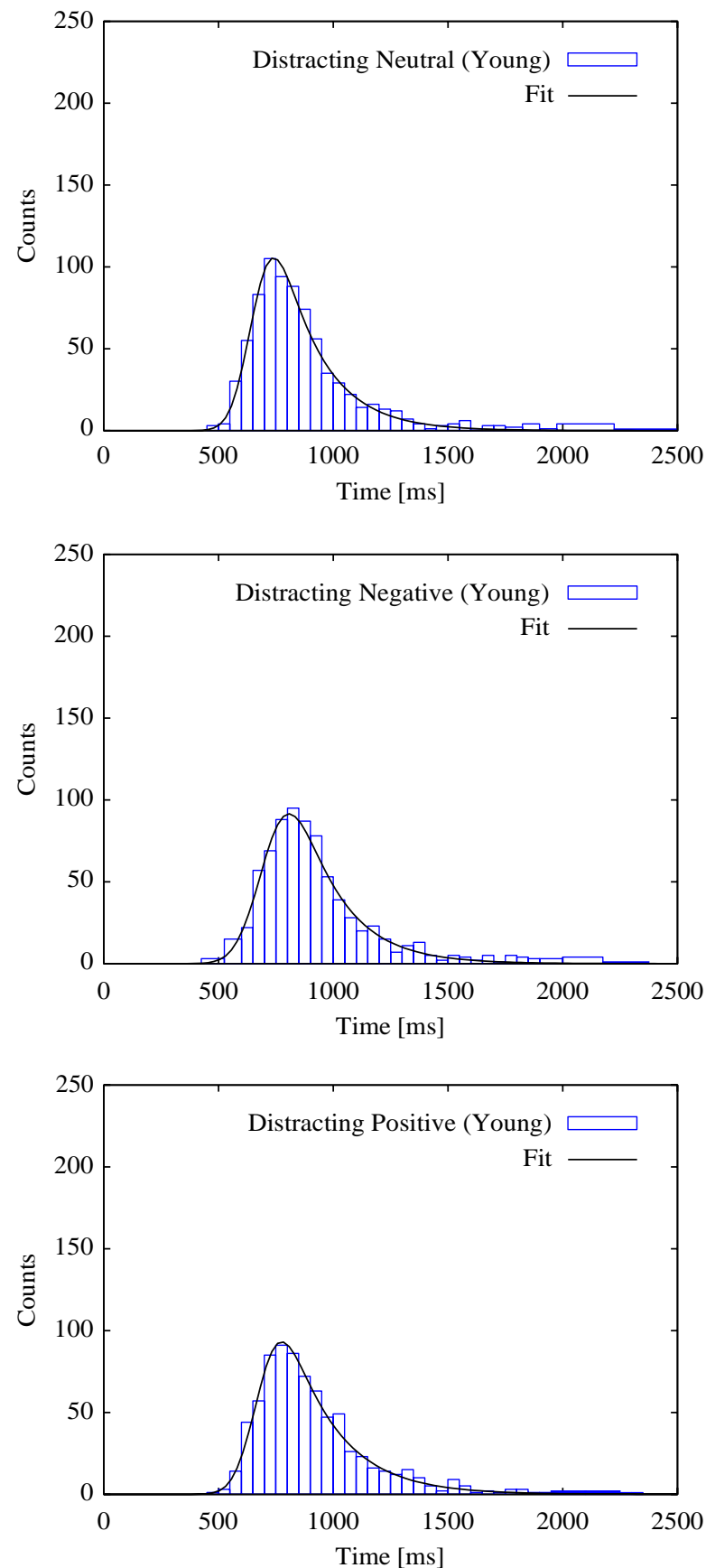

the uncertainties as a confidence interval length for each parameter. If we compare the distribution averages $(\mathrm{M}=\mathbf{I}+\mathrm{s})$, in the younger group, we notice that the differences between neutral and negative conditions for distractor stimuli (64.65) is much bigger than the uncertainties sum (46.56), indicating a significant statistical difference. The same pattern can be found for the differences between neutral and positive condition (54.31), which is much higher than the uncertainties sum (39.77).

Regarding the $\mathrm{S}$ parameter, the differences between neutral and positive condition (29.55) is slightly higher than the uncertainties sum (23.06). However, for the older participants neither the distribution average, nor the s parameter are higher than the
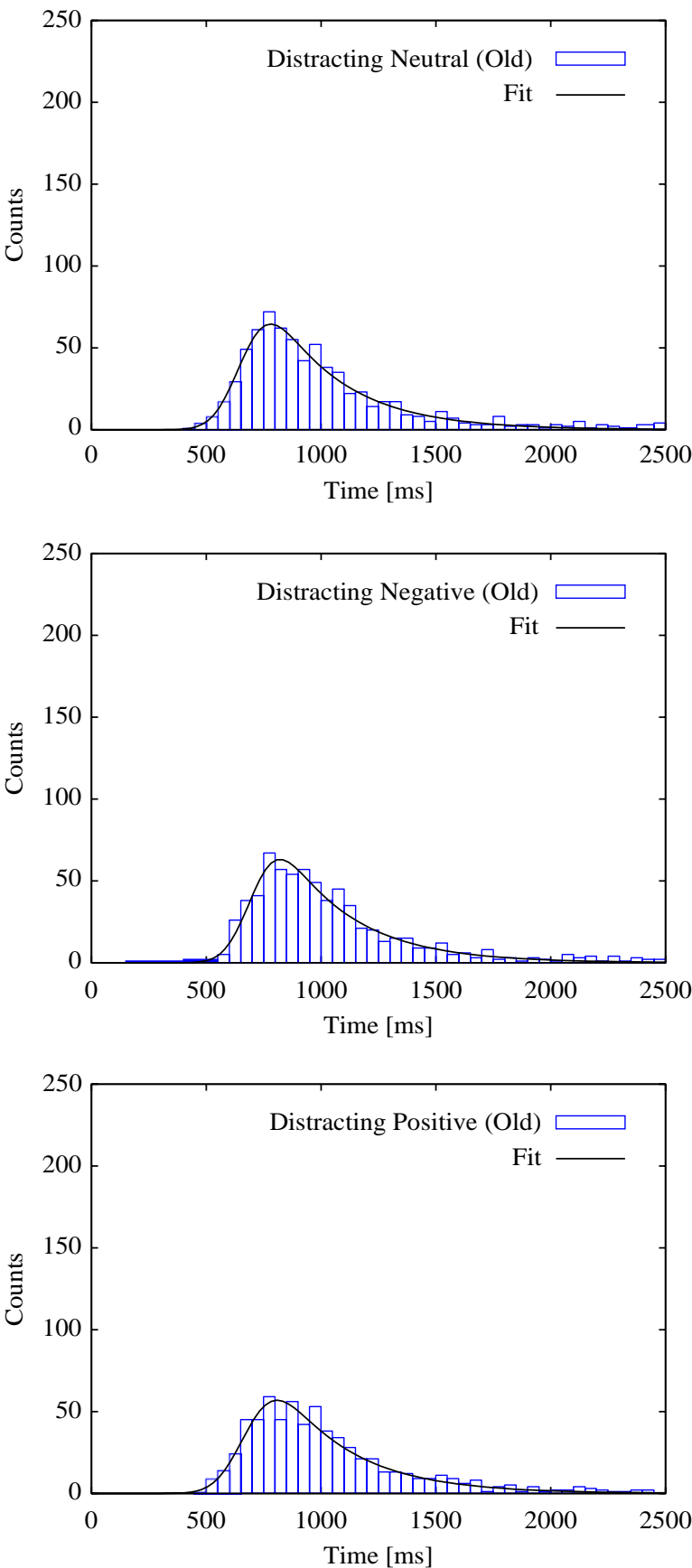

Fig. 2. Reaction times for each distracting condition, together with the ex-Gaussian fit. Left side: Young participants. Right side: Old participants. Top: neutral condition. Middle: negative condition. Bottom: positive condition. 
corresponding uncertainties sums. Finally, when we compare the parameters for older and younger participants, we notice that older participants present much higher distribution average and $\mathrm{S}$ parameter than the young younger participants.

\section{DISCUSSION AND CONCLUSIONS}

The aim of this study was to examine the influence of emotional valence and age on visual recognition, while controlling for the level of arousal and employing a short retention interval. This recognition task was analyzed not only by the classical analysis of variance, but also through the characterization of the reaction times via an ex-Gaussian fit which allows the analysis of the conditions in terms of parameters. The present work not only presents conclusions drawn from the classical ANOVA analysis, it also presents a study on the underlying cognitive processes that cannot be tackled by conventional techniques and so presents some of the advantages of the ex-Gaussian fit. This innovative technique does not depend on the same suppositions as the classical ANOVA, nor does it require the removal of outliers, which may exclude important information.

While the main aim of this study was to show the advantages of an ex-Gaussian fit analysis, the impact of age and emotional valence on recognition memory was evaluated as well. The impact of valence on RT appears to be much more prominent in the young group. We also found slower RTs towards negative stimuli, replicating Gordillo Leon et al.'s (2010) study. Carretié, Martin-Loeches, Hinojosa and Market (2001), postulated that there is a tendency to direct attention to negative stimuli, supporting the notion that the processing of the negative emotional charge could have had an essential role in our evolution. These results were clear for young participants, but differences did not reach statistical significance for the old ones. This evidence supports the explanation offered by Charles et al. (2003) about age-related reductions in memory for negative images.

Another point to highlight is the relation between memory and attention. In traditional models, memory involves attention, encoding, storage, and retrieval. In our experiment, both age groups were slower for negative images than others; however, the $S$ parameter cannot explain valence-linked age differences in memory. One alternative explanation, as Porto, Bertolucci,

Bueno (2011) indicated, is that the old participant's assessment might be biased due to the nature of emotional valence. They

claimed that older participants might focus more on picture details than valence. More research about this issue is necessary.

Addressing the question of RT parameters, the greater differences were found between age groups. Generally, RTs lower for young than old participants, indicating that old participants were slower. Furthermore, in light of the literature on the relation between the $\mathrm{s}$ parameter and attention, old participants appear to show poorer attentional performance.

Future studies may include a series of experiments that examine the role of the $\mathrm{s}$ parameter in the context of negative images, which try to explain if such pictures attract attention more readily or just hold attention for a longer period of time. Our data do not allow the disentangling between these explanations. Furthermore, it would also be interesting to evaluate the level of arousal, interactions between arousal and valence, and their relation to the S parameter. It would also be interesting to examine developmental changes through the study of the parameters, and also to explore the role of mood.

\section{REFERENCES}

Balota, D. A. \& Spieler, D. H. (1999). Word frequency, repetition, and lexicality effects in word recognition tasks: Beyond measures of central tendency. Journal of Experimental Psychology: General, 128, 3255.

Borg, C., Leroy, N., Favre, E., Laurent, B. \& Thomas-Antérion, C. (2011). How emotional pictures influence visuospatial binding in short-term memory in ageing and Alzheimer's disease? Brain and cognition, 76, 20-25.

Buchanan, T. W. \& Adolphs, R. (2002). The role of the human amygdala in emotional modulation of long-term declarative memory. Advances in Consciousness Research, 44, 9-34.

Carretié, L., Martín-Loeches, M., Hinojosa, J. A. \& Mercado, F. (2001). Emotion and attention interaction studied through event-related potentials. Journal of Cognitive Neuroscience, 13, 1109-1128.

Charles, S. T., Mather, M. \& Carstensen, L. L. (2003). Aging and emotional memory: The forgettable nature of negative images for older adults. Journal of Experimental Psychology: General, 132, 310324.

CSEA-NIMH. (1999). International affective picture system: Digitized photographs. Gainesville, FL: Center for Research in Psychophysiology, University of Florida.

Epstein, J. N., Langberg, J. M., Rosen, P. J., Graham, A., Narad, M. E., Antonini, T. N., et al. (2011). Evidence for higher reaction time variability for children with ADHD on a range of cognitive tasks including reward and event rate manipulations. Neuropsychology, 25, 427-441.

Forster, K. I. \& Forster, J. C. (2003). DMDX: A windows display program with millisecond accuracy. Behavior Research Methods, Instruments, and Computers, 35, 116-124.

Gordillo León, F., Arana, J. M., Mestas, L., Salvador, J., Meilán, J. J. G., Carro, J. Y. \& Pérez, E. (2010). Emocion y memoria de reconocimiento: La discriminacion de la informacion negativa como un proceso adaptativo. Psicothema, 22, 765-771.

Hohle, R. H. (1965). Inferred components of reaction times as functions of foreperiod duration. Journal of Experimental Psychology, 69, 382386.

Keil, A., Bradley, M. M., Hauk, O., Rockstroh, B., Elbert, T. \& Lang, P.J. (2002). Large-scale neural correlates of affective picture processing. Psychophysiology, 39, 641-649.

Lang, P. J. (1995). The emotion probe: Studies of motivation and attention. American Psychologist, 50, 372-385.

Lang, P. J. T., Bradley, M. M. Y. \& Cuthbert, B. N. (1999). International affective picture system (IAPS): Technical manual and affective ratings. Gainesville, FL: The Center for Research in Psychophysiology, University of Florida.

Leth-Steensen, C., King Elbaz, Z. \& Douglas, V. (2000). Mean response times, variability, and skew in the responding of ADHD children: A response time distributional approach. Acta Psychologica, 104, $167-190$

Luce, R. D. (1986). Response times: Their role in inferring elementary mental organization. New York: Oxford University Press.

Marquardt, D. (1963). An algorithm for least-squares estimation of nonlinear parameters. SIAM Journal on Applied Mathematics, 11, 431-441.

Matzke, D. \& Wagenmakers, E.-J. (2009). Psychological interpretation of ex-Gaussian and shifted Wald parameters: A diffusion model analysis. Psychonomic Bulletin and Review, 16, 798-817.

Moltó, J., Montañés, S., Poy, R., Segarra, P., Pastor, M. C., Irún, M. P. T., et al. (1999). Un método para el estudio experimental de las emociones: El International Affective Picture System (IAPS). Adaptación española. Revista de psicología general y aplicada: Revista de la Federación Española de Asociaciones de Psicología, 52, 55-87. 
Moret-Tatay, C. \& Perea, M. (2011). Is the go/no-go lexical decision task preferable to the yes/no task with developing readers? Journal of experimental child psychology, 110, 125-132.

Navarro-Pardo, E., Navarro-Prados, A., Gamermann, D. \& Moret-Tatay, C. (2013). Differences between young and old university students on lexical decision task: Evidence through an ex-Gaussian approach. Journal of General Psychology, 140, 251-268.

Pôrto, W. G., Bertolucci, P. H. F. \& Bueno, O. F. A. (2011). The paradox of age: An analysis of responses by aging Brazilians to the International Affective Picture System (IAPS). Revista Brasileira de Psiquiatria, 33, 10-15.

Ratcliff, R. \& Murdock, B. B. (1976). Retrieval processes in recognition memory. Psychological Review, 83, 190-214.
Reisberg, D. \& Heuer, F. (2004). Memory for emotional events. In

D. Reisberg, \& P. Hertel (Eds.), Memory and emotion (pp. 272-307). New York: Oxford University Press.

Rozin, P. \& Royzman, E. B. (2001). Negativity bias, negativity dominance, and contagion. Personality and Social Psychology Review, 5, 296-320.

Schupp, H. T., Stockburger, J., Codispoti, M., Junghofer, M., Weike, A. I. \& Hamm, A. O. (2007). Selective visual attention to emotion. Journal of Neuroscience, 27, 1082-1089.

Wright, D. B., Busnello, R. H. D., Buratto, L. G. \& Stein, L. M. (2012). Are valence and social avoidance associated with the memory conformity effect? Acta Psychologica, 141, 78-85 